\title{
BALANÇO HÍDRICO CLIMATOLÓGICO PARA O MUNICÍPIO DE JANUÁRIA - MG
}

\author{
Ailton Rodrigues de Oliveira ${ }^{1}$ \\ Rodrigo Nogueira Martins ${ }^{2}$ \\ José Ângeles Moreira de Oliveira ${ }^{3}$ \\ Juciara Oliveira Lopes ${ }^{4}$ \\ Antônio Fábio Silva Santos ${ }^{5}$
}

Resumo: O presente trabalho objetivou elaborar as normais climatológicas de temperatura e precipitação e o balanço hídrico mensal para as condições climáticas da cidade de Januária. O balanço hídrico médio mensal foi elaborado pelo método proposto por THORTHWAITE \& MATHER (1955), com dados meteorológicos do período de 2006 a 2015. Para isso, estimou-se a evapotranspiração potencial pelo método de Thornthwaite (1948), adotando uma capacidade de água disponível (CAD) média de $100 \mathrm{~mm}$. Com isso, foram obtidas as normais climatológicas por meio das médias mensais da precipitação e temperatura média compensada. O município apresentou um período de sete meses sequenciados de deficiência hídrica, com um déficit total de 460,7mm, distribuído nos messes de abril a novembro, sendo o mês de setembro o de maior deficiência chegando a $111,0 \mathrm{~mm}$, o excedente hídrico totalizou $55,2 \mathrm{~mm}$ distribuídos em dois meses, sendo dezembro e março com 41,1 mm (74,5\%) e 14,1 mm (25,5\%), respectivamente.

Palavras-chave: Evapotranspiração; Deficiência hídrica; Dados meteorológicos.

\footnotetext{
${ }^{1}$ Instituto Federal do Norte de Minas Gerais - IFNMG Campus Januária - Departamento de Engenharia Agrícola e Ambiental, Brasil. E-mail: ailton.r.oliveira@outlook.com.

2 Instituto Federal do Norte de Minas Gerais - IFNMG Campus Januária - Departamento de Engenharia Agrícola e Ambiental, Brasil. E-mail: rodrigonmartins@hotmail.com

3 Instituto Federal do Norte de Minas Gerais - IFNMG Campus Januária - Departamento de Engenharia Agrícola e Ambiental, Brasil. E-mail: j.ngeles@yahoo.com

${ }^{4}$ Instituto Federal do Norte de Minas Gerais - IFNMG Campus Januária - Departamento de Engenharia Agrícola e Ambiental, Brasil. E-mail: juciaraoliveiralopes@yahoo.com.br.

5 Mestre em Produção Vegetal no Semi-Árido, Instituto Federal do Norte de Minas Gerais - IFNMg Campus Januária - Departamento de Engenharia Agrícola e Ambiental, Brasil. E-mail: antoniofab10@yahoo.com.br.
} 